\title{
Introduction
}

\section{Interjections: \\ The universal yet neglected part of speech}

\author{
Felix Ameka*
}

\begin{abstract}
"We see such 'expression' [e.g. Oops! F.A.] as a natural overflowing, a flooding up of previously contained feeling, a bursting of normal restraints, a case of being caught off guard. That is what would be learned by asking the man in the street if he uses these forms and, if so, what he means by them."
\end{abstract}

(Goffman 1981: 99)

\section{Preliminaries}

It is perhaps true that apart from nouns and verbs, interjections - those little words, or 'non-words', which can constitute utterances by themselves - are another word class found in all languages. But it is also true that this class of items has eluded description and has, for the most part, been ignored in theoretical linguistics discourse (cf. Ehlich 1986 and Wilkins, 1992 (this volume)). Indeed as Schachter rightly observes: "Although there are a good many linguistic descriptions that fail to mention interjections, it seems likely that all languages do in fact have such a class of words" (Schachter 1985: 60).

Correspondence to: F. Ameka, Department of African Linguistics, University of Leiden, P.O. Box 9515, NL-2300 RA Leiden, The Netherlands.

* I would like to thank Lisette Frigo, Debbie Hill, Harold Koch, Tim Shopen, Jane Simpson, Anna Wierzbicka and David Wilkins for their comments and criticisms on an earlier version of this paper. I would also like to thank all the authors for their co-operation and contributions to this Special Issue. I am also grateful to Debbie Hill, Anna Wierzbicka and the editors of the Journal of Pragmatics and all the people who served as anonymous referees for the papers in this issue for all their help and advice in the editorial enterprise. Special thanks are due to my colleague and friend Debbie Hill without whose untiring efforts, help and support, the editorial work on this issue could never have been completed. 
This state of affairs can be attributed partly to the history of the study of interjections and partly to their nature. Syntactically, the same label, interjection', has been used to describe a word class and an utterance type which leads to some confusions. Interjections as a word class have different degrees of affinity with other items such as particles and routines, and they have sometimes been subsumed under these items (cf. e.g. Östman 1981, Coulmas 1981, James 1973a and also Kryk 1992, Evans 1992, and Wilkins 1992). On other occasions, interjections are analysed together with these items and connectives in terms of their discourse marking function and hence have been called discourse markers (cf. e.g. Schourup 1985, Zwicky 1985, Schiffrin 1987, and see also Kryk 1992).

In this introduction to the present Special Issue of the Journal of Pragmatics dedicated to interjections and similar items, I want to attempt to draw out and suggest solutions to the confusion that has beset these important items. They form a significant subset of those seemingly irrational devices that constitute the essence of communication. I will propose a definition and a classification of interjections. For an appreciation of the views expressed, a brief description is offered on the history of the analysis of intcrjections. To make the discussions accessible, most of the examples are taken from English.

\section{A history of the part of speech 'interjection'}

The Greek grammarians treated interjections as a subclass of adverbs since it was thought that they like other adverbs 'determine' the verb even if the verb is understood.

Interjection or interiectio was recognised as a separate part of speech by the Latin grammarians. This new part of speech made it possible for the Latin grammarians to keep the number of the 'partes orationis' to the 'magic' number eight. It replaced the article class of the Greeks since Latin did not have an article.) Priscian, we are told, found that the interjection required no syntactic union with any part of the sentence and defined this part of speech as "pars orationis significans mentis affectum voce incondita", 'a part of speech signifying an emotion by means of an unformed word i.e. one not fixed by convention" "(Padler 1976: 266). Other scholars of the same period consider interjections as a class of words which are syntactically independent of verbs, and indicate a feeling or state of mind (Robins 1979: 58).

Three things are noteworthy about the views of Latin grammarians on interjections: first, the implication that interjections include items which were thought of as 'non-words'; second, interjections were thought of as being syntactically independent; third, interjections are said to signify a feeling or state of mind. 
Some of the Modistae such as Martin of Dacia and Thomas of Erfurt reverted to the Greek tradition and insisted on the intimate link between the verb and the interjection although with different emphasis. According to Thomas of Erfurt, "The general essential mode of signifying of the interjection is the mode of signifying by means of the mode of determining something, which is the verb or participle representing states of mind. For since the mind is influenced by the emotions of pain, joy, fear and the like, this is expressed by means of interjections. Hence the interjection determines the verb or participle, not in a simple fashion, but in relation to the mind, expressing the state of the mind" (Bursill-Hall 1971: 269). However, others recognised the syntactic independence of interjections. Thus Siger of Courtrai identifies interjections as a part of speech which "is used to signify various states of mind as apprehended by the intellect; it is close to the verbum since such emotional states will be caused by the feature of movement but it does not signify the concept of the mind by determining the verb or participle in particular" (Bursill-Hall 1971: 120, 284). Another Modista, Boethius of Dacia, also echoes the idea of the interjection as an unconventional word or "non-word': "interiectio significat affectum mentis et hoc voce incognita". That is, the interjection signifies the affect of the mind, and this via an unknown [or unanalyzable] vox' (McDermott 1980: 124-125).

Perhaps another view about interjections worth noting is that of John Wilkins. He treats interjections as sentence substitutes (cited in Padley 1985: 376). Padley suggests that this view was probably inspired by that of Campenalla for whom an interjection is not a simplex word. Thus interjections are strictly speaking not a part of speech because they are not words but rather an element of syntax.

Thus far it is clear that interjections have been treated as a part of speech by the Latin grammarians and some Modistae but as an element of syntax by Wilkins following Campenalla. These two perspectives have remained and have become a source of confusion in the present day treatment of interjections (see below). Basically, the term interjection tends to be used both for a word level category and for a sentence level category. The suggestion to be made here is that the term interjection should be reserved for the word class and that at the sentence level these words should be analysed together with other exclamatory sentences as exclamations.

Twentieth century linguists, one could say, have pointed to the subclasses of interjections that may be found in a language. Some of them, for instance Jespersen, have implied in their discussion that the interjection does not constitute a separate part of speech:

\footnotetext{
"As a last part of speech the usual lists give interjections, under which name are comprised both words which are never used otherwise (some containing sounds not found in ordinary words e.g. an inhaled $f$ produced by sudden pain, or the suction stop inadequately written tut and others
} 
formed by means of ordinary sounds e.g. hullo, oh), and on the other hand words from the ordinary language e.g. Well! Why? ... Nonsense! ... The only thing that these elements have in common is their ability to stand alone as a complete utterance; otherwise they may be assigned to various word classes. They should not therefore be isolated from their ordinary uses. Those interjections which cannot be used except as interjections may most conveniently be classed with other particles." (Jespersen 1924: 90)

Here Jespersen suggests that those words which belong to other parts of speech such as noun, verb, etc. but which can be used by themselves as non-elliptical utterances should not be put in a separate class. This is an important observation because part of the confusion that surrounds the interjection word class today stems from the fact that analysts mix up functions and categories (see below). However I cannot agree with the other point that Jespersen makes concerning classifying those interjection words which are not used otherwise together with particles. This suggestion goes back to traditional grammar where uninflected words constituted a big class. I will argue below that particles are different from interjections in spite of the fact that they may all be uninflected.

Bloomfield uses the term interjection as a term for forms that "occur predominantly as minor sentences, entering into few or no constructions other than parataxis" (1933: 176ff.). They are "either special words such as ouch, oh, sh, gosh, hello, sir, ma'am, yes, or else phrases (secondary interjections) often of peculiar construction, such as dear me, goodness me, goodness gracious, goodness sakes alive, oh dear, by golly, you angel, please, thank you, good-bye". Bloomfield goes on to classify minor sentences into 'completive' and 'exclamatory' ones and different interjections fall into one or the other type with other minor sentences. For instance yes and no fall together with other answer phrases into the completive type. Bloomfield uses the term interjection here to cover words and phrases and the latter are identified as secondary interjections. I think the concept of secondary interjection is a useful one, and I am going to invoke it in my classification below. However I would advocate that the term interjection be reserved for words while those phrases which behave like interjections, that is, Bloomfield's secondary interjections, be referred to as interjectional phrases. At the sentence level, interjections and interjectional phrases together with other utterances can be classified as completive or exclamatory utterances. It will also become apparent that some of the items listed by Bloomfield are not true interjections but may best be analysed as formulaic words. In the rest of this introduction I will suggest and defend a definition and a typology of interjections that draws on insights from these and other studies of interjectional phenomena. 


\section{Towards a definition and a typology of interjections}

\subsection{Primary interjections}

For a proper understanding of the phenomenon of interjections in the languages of the world, it seems useful to distinguish between those words that are primary interjections, that is, they are not used otherwise; and other words which come to be used as interjections by virtue of their notional semantics. These may be considered secondary interjections. The implication of this view is that secondary interjections are forms that belong to other word classes based on their semantics and are interjections only because they can occur by themselves non-elliptically as one-word utterances and in this usage refer to mental acts.

Primary interjections are little words or non-words which in terms of their distribution can constitute an utterance by themselves and do not normally enter into construction with other word classes, for example, Ouch!, Wow!, Gee!, Oho!, Oops!, etc. They could be used as co-utterances with other units. Consider this example:

Gee, you look like you had it! (Williams 1961: 8)

In this usage, they are related to connectors which always occur with another utterance - hence their discourse marking functions. It must be stressed however that connectors cannot stand alone as utterances, unless they are used elliptically. Compare:

Oh, I have another suit.

And, I have another suit.

$\mathrm{Oh}$ !

"? And

Although oh and and seem to fill similar structural slots in the first pair of examples, and cannot occur as an utterance by itself without being elliptical. And is therefore not an interjection. If and was used as an elliptical utterance it usually carries a rising intonation signalling that it is an incomplete utterance. Thus the interlocutors would interpret the speaker as saying something more is to be added: either the speaker wants to say something more or $\mathrm{s} / \mathrm{he}$ wants the addressee to say something more in addition to what has been said previously. This is perhaps true of discourse particles as a whole.

Primary interjections as some of the examples above show tend to be phonologically and morphologically anomalous. They may thus be made up of sounds and sound sequences that are not found in other parts of the language. In English the interjection spelt tut-tut is phonetically a series of 
dental clicks - sounds which are not used otherwise in the language. Some English interjections do not contain any vowels, for instance, psst!, sh!. From the point of view of the main sound system of English these are "non-words". However, phonological anomaly is not a definitive criterion for the class of items because there are other interjections which conform with the patterns of the main sound system. Nevertheless this property of some of them has led to one of the reasons for the neglect of interjections because they are thought of as peripheral to the main sound system and linguists for a long time were not concerned with peripheral elements (see below). Indeed, as Wilkins (1992) demonstrates, phonological aberrance is not restricted to interjections but is a feature also of other deictic elements in natural languages such as pronouns and demonstratives. Yet "no one has ever tried to claim that pronouns and demonstratives are not part of the core of the language system" (Wilkins 1992: 135).

Morphologically, interjections do not normally take inflections or derivations in those languages that make use of such forms. This is one of the reasons why they have been classified together with particles and other uninflected words like adverbs. It should be noted here that some interjections which evolve from verbs could carry a particular inflection but they do not obey the agreements rules of the language in question. In other words the inflections together with the verb stem have become frozen and form a completely new word. Notice that although the form tiens! 'look!, hey!, here! etc.' is homophonous with the second person singular form of the verb tenir 'to hold', tiens! is used as an interjection to both singular and plural auditors (cf. Hérique in press).

Interjections are relatively conventionalised vocal gestures (or more generally, linguistic gestures) which express a speaker's mental state, action or attitude or reaction to a situation (cf. Goffman's response cries and the views of ancient and medieval grammarians). The use of the phrase 'relatively conventionalised' in the above characterisation is meant to reflect the semiopen nature of the class of interjections. New interjections can be coined the way new nouns can be added to the lexicon. It must be emphasised that the broad description of interjections as forms that express a speaker's mental state is meant to avoid the common claim that interjections are only emotive. After all there are different mental states and the emotive is but one of them (see the classification below).

The definition of interjections adopted in this discussion is one of a number of perspectives that one-may take in describing these items. I have used semantic and structural criteria in defining the grammatical class of interjections (see also Wierzbicka 1992a). Others define interjections using formal criteria (see Wilkins 1992 and Evans 1992). From this point of view interjections are a subclass of the particle class, where the term particle is used in a pretheoretical sense to refer to uninflected words. 
From a pragmatic point of view, interjections may be defined as a subset of items that encode speaker attitudes and communicative intentions and are context-bound. In this approach interjections are a subclass of a large class of pragmatic markers (cf. Fraser 1990). Ultimately, one would have to apply a number of different criteria to subclassify the pragmatic markers. For example, on the basis of distribution as utterances one can identify a subclass of pragmatic markers as routines and another subclass as particles. Routines may be taken to be those expressions which can occur on their own as utterances. Particles on the other hand cannot occur on their own as utterances. Since interjections can constitute utterances by themselves they may be viewed as a subclass of routines but not of particles (see below for further clarification and see Fraser (1990) for a different typology of pragmatic markers which is not incompatible with the views expressed here).

The term 'particle' is used here in a restricted sense (taking Zwicky's (1985) reservations into account). A particle is a little word which is syntactically dependent on other elements in the clause and is well integrated into the clause in which it occurs. Particles are typically used to express speaker attitudes or perspectives towards a proposition and to modify the illocutionary force of utterances. Typically such words do not have propositional content in terms of speech act theory. There are several subclasses of such items across the world's languages. This class of particles includes information status indicating forms usually labelled topic and focus marking particles in various languages; illocutionary function indicating words such as the utterance particles in several Asian and African languages; modal particles in the Germanic languages, for example, hoor 'you hear' in Dutch, and scalar and focus particles, for example, English even, only, almost etc. (see König 1991).

This class of particles excludes the items that have come to be known as discourse markers or particles or pragmatic particles. Unlike the class of particles described here, which is a lexical/grammatical category, the class of discourse markers is a functional category. As Fraser (1990: 387) notes the elements that belong to this category are grouped together on the basis of their pragmatic function, namely, they indicate the way a speaker intends a subsequent discourse fragment to be related to the previous unit. Discourse markers are also typically not well integrated into the grammar of the clause whereas particles are. Furthermore, particles as they are defined here may develop into or may function sometimes as discourse markers.

Thus particles and interjections are distinct lexical/grammatical classes. Particles cannot constitute an utterance by themselves, interjections are lexical utterances. Both classes are different from the functional or pragmatic class of discourse markers. Members of either the particle or interjection class may function as discourse markers. It is needless to say that these views may not be shared in their details by every researcher in the field. This 
is a first attempt to make sense of the conceptual and terminological confusion that is prevalent in the field of particle and interjection studies.

\subsection{Interjections vs. 'illocutes'}

\subsubsection{Interjections vs. particles}

Interjections share with other 'illocutes', viz., particles, vocatives and routines in general, their context-boundedness. ${ }^{1}$ That is, they are all produced in reaction to a linguistic or extra-linguistic context, and can only be interpreted relative to the context in which they are produced. Nevertheless, interjections form a distinct class. They differ from particles in their relative syntactic independence. That is, whereas particles are fully integrated into the syntax of utterances and cannot constitute utterances by themselves, interjections can be utterances by themselves and they are always separated by a pause from the other utterances with which they may co-occur. They always constitute an intonation unit by themselves. Thus interjections are only loosely integrated into the grammar of the clause. This feature of interjections as both words and utterances sets them apart from other word classes including particles. At the same time it poses problems for the analyst who would like to fit them somewhere on the hierarchy of grammatical units (see Wilkins 1992; and also Ehlich 1986, who views interjections as linguistic units in which the distinction between word and sentence is neutralised). To avoid confusion it is suggested that the term interjection be reserved for the word class, while at the sentence or utterance level these items should be analysed together with other utterance types as exclamations.

\subsubsection{Interjections vs. routines}

The relationship between interjections and routines or formulae is a bit more complex. If one thinks of routines as "highly conventionalised prepatterned expressions whose occurrence is tied to more or less standard communication situations" (Coulmas 1981: 2-3) which are produced automatically (or semiautomatically), it can be claimed that interjections are a type of routines. For they are tied to specific situations and their pragmatic function is that of being used in reaction to an element in the linguistic or extra-linguistic context of the speech event (cf. Laughren 1982). Typically, however, one can distinguish between primary interjections as a part of speech and other types of routines since the latter tend to be multi-word expressions (cf. Evans 1992).

Nevertheless complications arise with respect to one word formulae such as sorry, bye, etc. What is more, some of the multi-word expressions tend to undergo lexicalisation and develop into one word, for instance thankyou.

1 I learnt from Anna Wierzbicka that Dwight Bolinger coined the nice term 'illocutes' to cover various illocutionary linguistic items. 
These one word formulae like true interjections can constitute non-elliptical utterances by themselves; however, I think there are some subtle differences between the two types of words. The interjections are spontaneous immediate responses to situations while the formulae are intentional and (socially) expected reactions to situations. Note that formulae are said to be surrogates for the true feelings that people have (Matisoff 1979). Interjections can hardly be described as such.

Consider the meaning conveyed by thankyou and wow! as reactions to a situation where one has received a surprise gift. The meanings of both forms could be decomposed and represented in a metalanguage of semantic primitives based on English as follows (cf. Ameka 1987, 1992; Wierzbicka 1987, 1992; and Wilkins (1992):

\section{thankyou}

I now know this: you have done something good for me

[I feel something good towards you because of that]

I want to say the kind of thing one should say to another when things of this kind happen

I say: I feel something good towards you because of what you have done for me

I say it because I want to cause you to know what I feel and to cause you to feel something good

Wow!

I now know something has happened

I wouldn't have thought it would have happened

I think this is very good

I feel something good because of that

I say this: [wao] because I want people to know this

A number of differences are noticeable between the two forms as used in the same context when one compares the explications above. First, there is no addressee 'you' in the formula for wow! while it is present in that of thankyou. (Needless to say 'you' is part of the item itself.) One piece of evidence in support of this is in the report of the two utterances. Compare the acceptability of the following:

She said thankyou to him, when he gave her the money.

"She said wow to him, when he gave her the money.

A more general point is that primary interjections do not have addressees, but formulae have addressees. Interjections such as the conative and phatic ones may be directed at people, but they are not addressed to people (see section 4 
below). Formulae on the other hand are addressed to specific people as the linguistic evidence above suggests (see Ameka 1992 in this issue for further arguments on this point). Related to this difference is the observation made by Goffman $(1981: 97,104)$ that linguistic activities involving interjections are not conversational encounters although they may be socially situated. Formulae, I think, are both socially and conversationally situated.

Second, there is no component about the social convention and predictability of the form found in the definition of wow! (see the third component for thankyou).

Third, there is no dictum - an 'I say: ...' component - in the explication for wow!. This last difference points to a contrast between formulae in general, and formulaic words in particular, and interjections. The former are speech acts, while the latter are mental acts - they refer to mental states and dispositions of the speaker. ${ }^{2}$ (The issue of whether interjections are speech acts or not is discussed in the contributions of Wierzbicka, Wilkins and Ameka to this issue.) In this respect, interjections and formulae are also different from particles, which are neither speech acts nor mental acts but modifiers of illocutionary acts.

Nevertheless, interjections and formulac share a number of commonalitics: both are forms of language that are found in most if not all languages, yet they encode culture specific meanings in these languages; both forms are indexical - the formulae are social deictics, indexing elements of the social relationships between the speaker and addressee, etc.; while interjections are symptomatic of the speaker's state of mind (and the context) (cf. Wilkins 1992 and Evans 1992 on the deictic nature of interjections). It is traditional for both types of words to be described as interjections, but such a use of the term interjection is too broad, in my view (see Wilkins 1992, who argues that both types of words are interjections).

If the differences in the semantic structure of these two types of words noted above are essentially correct, then there is the need, in my view, to recognise two separate semantically defined word classes or at least two subclasses of a large form class: formulaic words and interjections; even

2 It may be instructive here to draw attention to the views of Charles Fries. He classified free utterance units into communicative utterances, e.g. greetings, calls and questions, commands and statements on the one hand and noncommunicative utterances which are utterances characteristic of situations, such as surprise, sudden pain, prolonged pain, disgust, anger, etc. on the other. The noncommunicative utterances are those that are not directed to a listener and they are not used to elicit a particular response as the communicative utterances are (Fries 1952: 52-53). The examples and description make it clear that the noncommunicative utterances are interjections. In fact, Fries expresses this view in a footnote where he notes that his noncommunicative utterances are sometimes classed as interjections. Without necessarily subscribing to the implications of the term 'noncommunicative utterances', one could interpret this classification as one between speech acts and non speech acts. In this respect the suggestion that interjections are not full-fledged speech acts is consistent with Fries's analysis 
though most descriptive grammars lump these two together as interjections. To take one example at random, for Leech et al. "Interjections are rather peripheral to language: words like $u g h$, phew, oh, ah and ouch are linguistically somewhat primitive expressions of feeling, only loosely integrated into the linguistic system. We can include here too swear words (damn etc.), greetings (hello) and other signalling words like goodbye, yes, no, okay etc." (1982: 53; emphasis added). Thus for Leech et al. the interjection class includes true interjections and formulae: their greetings and signalling words. Two other aspects of their definition require further examination: first the issue of the peripherality of interjections, and second, the status of swear words vis-à-vis interjections. Before discussing the peripherality of interjections, it might be useful to identify what I construe secondary interjections to be. I would claim that swear words are a subset of secondary interjections.

\subsection{Secondary interjections}

Secondary interjections are those words which have an independent semantic value but which can be used conventionally as utterances by themselves to express a mental attitude or state. ${ }^{3}$ They thus refer to mental acts too. Under secondary interjections fall such alarm calls and attention getters as Help!, Fire!, Careful! and swear and taboo words such as damn!, hell!, heavens!, Christ! and other emotively used words such as Shame!, Bother!, Drats!, etc.

To summarise thus far, it has been suggested that interjections are a class of words which can stand on their own as utterances and which refer to mental acts. These words may be of two types: primary or secondary. These words are related to but are also different from formulae and particles. It has been assumed implicitly in the discussion so far that interjections are simple monomorphemic words. It seems however that different interjections have different degrees of formal complexity. Thus there are multi-morphemic ones which constitute a phonological word such as Goddammit!. These may be referred to as complex interjections. The French forms of oh là là!, he là! and hop là! for instance may be included.

Apart from these there are multi-word expressions, phrases, which can be free utterance units and refer to mental acts, for example, bloody hell!, dear me!, My Goodness!, Thank God!, etc. I propose to call these utterances 'interjectional phrases' (cf. Hill 1992). As utterances, interjections and interjectional phrases can be classified along with a host of other utterances as exclamations. The point is that interjection as a label characterises a class of words and should not be used confusingly to describe utterance types.

3 It should be recalled that the use of the term secondary interjection here is different from that of Bloomfield (1933: 136) as pointed out above. I am going to propose the term 'interjcctional expression' for the sorts of items that Bloomfield called secondary interjections. 


\subsection{On the peripherality of interjections}

There are at least three senses in which people talk about interjections as being peripheral to language. One of these is the sense which is embodied in the definition of Leech et al. quoted above. That is, interjections are peripheral to language as a whole; they are paralinguistic. In this conception of interjections, they "are only the outskirts of real language. Language begins where interjections end" (Müller 1862: 366). Interjections are viewed as an accompaniment to language or communication rather than being a form of linguistic or verbal communication themselves. It is significant that among the paralinguistic vocalisations, there is a subset which are conventional items and which analysts always separate out from the rest (see for example Trager's 1964: 277 vocal segregates and Goffman's 1981 different categories of response cries, one of which is interjections). There is no doubt that there is an intimate connection between interjections and gestures in general. Questions have even been raised as to whether there is a boundary between interjections as vocal gestures and physical gestures (cf. Goffman 1981: 122; Eastman 1992, and Wilkins 1992). Interjections seem to be on the boundary between verbal and non verbal communication. From that point of view it seems true that interjections are somehow peripheral to language. However, this should not be used as an excuse not to investigate what their peculiarities are from a linguistic point of view because like other linguistic items they are conventional, language specific elements. Furthermore, as argued by Wilkins (1992; and see also Juntanamalaga and Diller 1992), it is the study of the peripheries of language which will provide the answers to many of the current concerns of linguistics.

Another interpretation of the peripherality of interjections is based on their syntactic independence. Since interjections do not enter into construction with other elements they are not very well integrated into the clause grammars of languages. Finally, because some interjections are made of sounds that are not found elsewhere in the language system, they are said not to belong to the main sound system (see earlier discussion of the phonological aberrance of interjections).

In fact, these interjections share their anomalous phonological nature with onomatopoeic words. For this reason, descriptive grammars usually include onomatopoiec words and iconic depictives as a subclass of interjections (see e.g. Sapir's Takelma grammar, and see Kryk 1992 on a summary of the views on interjections in English and Polish). Perhaps this is the result of a confusion between phonological class and a grammatical class. I think onomatopoeic words form a phonological class whose members may belong to different grammatical classes. This should not be misconstrued to imply that some interjections are not iconic with the meanings that they convey. Interjections do display a fair amount of sound symbolism and from that point of 
view some interjections could be onomatopoeic (see for example Jespersen 1921: $597 \mathrm{ff}$., and also Wierzbicka 1992a).

Nevertheless, one can still distinguish between interjections and onomatopoeic words and ideophones. First, onomatopoeic words, etc. tend to be descriptive, rather than expressive of a mental state as interjections are (cf. Evans 1992). Second, the ideophones, etc., may not be able to stand on their own as utterances without being elliptical. Notice that the use of interjections as utterances in themselves does not involve ellipsis.

Different interjections do have different degrees of integration within the linguistic systems of languages (cf. Stankiewicz 1964). But the underlying commonality shared by all words which satisfy our characterisation of interjection is that they are linguistic signs. As such they deserve to be studied by linguists. This is a view shared by all the contributors to this volume.

\section{Towards a classification of interjections}

In this section a classification of interjections will be proposed based on the specific communicative functions they fulfil and according to the types of meaning they predicate (cf. Isačenko 1964: 96). I assume that one of the ways (but by no means the only one) in which one can classify interjections is to appeal to the functions of language which have been traditionally proposed by people like Bühler (1934) and modified by Jakobson (1960), for instance (see Lyons 1977 for an overview). Three categories that are particularly relevant for this are the expressive, with focus on the speaker's state, the conative, with emphasis on the speaker's wishes, and the phatic which has to do with the establishment of contact.

Expressive interjections may be characterised as the vocal gestures which are symptoms of the speaker's mental state. They may be subdivided into two groups: the emotive and the cognitive. The emotive ones are those that express the speaker's state with respect to the emotions and sensations they have at the time. For example, Yuk! 'I feel disgust'; Wow! 'I am surprised'; Ouch! 'I feel pain'; Ugh! 'I feel disgust' (see Wierzbicka 1992). Cognitive interjections are those that pertain to the state of knowledge and thoughts at the time of utterance. Examples include: Aha! 'I now know this'; (Ewe) ehe! 'I now remember'.

Conative interjections are those expressions which are directed at an auditor. They are either aimed at getting someone's attention or they demand an action or response from someone of a speaker's wants. "The aim of conation", as Isačenko (1964: 91) points out, "is to provoke a reaction on the part of the listener". For instance, sh! 'I want silence here'; $e h$ ? 'I want to know something'; Russian $a^{\prime} u$ which is used to keep contact with people and Australian English cooee which is used to locate people in the bush. Calls to 
animals etc. also belong here as conative interjections (see e.g. Bynon 1976 and Ameka (1992).

Phatic interjections are used in the establishment and maintenance of communicative contact. A variety of conventional vocalisations which expresss a speaker's mental attitude towards the on-going discourse, that is backchanneling or feedback signalling vocalisations, may be classified as phatic. For example, $m h m, u h-h u h$, yeah. Included in this class are interjections used in the performance of various interactional routines. For example, there are interjections (as opposed to formulae) for greeting, farewelling and welcoming people (see Ameka 1992 on the use of atúu! in the languages of southern Ghana, and also Evans 1992).

It must be stressed however that a particular item may have multiple functions and hence multiple categorisation. For instance, it is possible to think that the backchanneling interjections could be cognitive since they signal the current state of the utterer with respect to their comprehension and mental involvement in the on-going communication. Similarly, the expressive interjections have an associated conative element. Although they are not directed at an addressee, their emission could evoke a response in a by-stander. The classification is based on what is perceived to be the predominant function of the item in question with respect to its semantics.

\section{Summary}

It is quite customary for interjections to be described in terms of the functions they may serve in discourse. Thus some of them at least have been described as discourse markers or particles (Zwicky 1985, Schourup 1985, Schiffrin 1987 and see also Kryk 1992 and Evans 1992). That is, they may serve to mark the boundaries of discourse units. It is important to realise that it is only certain interjections that may be used for this function. Furthermore, the interjections which can be discourse markers constitute just one set of a number of other linguistic elements such as verbs, deictics, adverbials and connectives which can perform this function (see for example, Schiffrin 1987: 328). Thus this discourse function by itself does not define the class of interjections nor should the two terms be deemed to be coterminous.

Similarly, some interjections can function as interrogative tags, for instance,

It is tasty, eh?

It is tasty, huh?

However there are a number of other units that can perform the same function, for example, right?, don't you think?, isn't it?, etc. Perhaps here as 
elsewhere in linguistic analysis what is needed is a clear distinction between functions and the categories of elements that have this function.

Another point to be emphasised is this: the same form can have multiple categorisation. It is not uncommon to find the same form functioning as an interjection and as a particle or a formulaic word. For example, hey in English may function as a conative interjection, or it may function as a vocative particle when it is used with names (see also Kryk 1992, Wilkins 1992 and Juntanamalaga and Diller 1992, all in this volume). Let me illustrate this point further with the forms yes and no which Bloomfield (1933: 177) classified as completive interjections. In the perspective adopted in the present discussion, yes is an interjection when used as a backchannel. It is a formulaic word when it is used as a response to a polar question or an offer as in the excerpt below:

Q: Have you seen 'The Gods must be crazy II'?

A: Yes.

As a feedback signal of an auditor in continuous discourse yes is a mental act, while as a response, it is a speech act. No on the other hand is not an interjection, at least not in the sense in which the term is used in this discussion. It does not get used as a backchannel signal as yes does. ${ }^{4}$ It combines, however, with oh to form a complex interjection oh no!. It can also be used as an exlamatory response to reject an offer: no!. No can also be used as an adverbial, as in the sentence:

\section{It's no use to me.}

The only class membership that yes and no share is, I suggest, that of formulaic words - their use in response to propositional questions. It seems that one can achieve a fine grained characterisation of interjections if we investigate their semantics and pragmatics.

4 Jane Simpson (private communication) suggests that some people can use no as a backchanneler in a context like the following:

A: Fred got married to Sue last night.

B: No! [i.e. keep talking this is amazing news]

Several native speakers of (Australian) English react in different ways to this exchange. Many informants did not find it a natural usage, but others felt it was marginally possible. Some commented that it could be an American usage. The only conclusion one can draw from this is that there may be variation here between dialects and individuals. It appears the norm is that no is not commonly used in providing auditor feedback. There is also a difference in the behaviour of yes and no when they are used as responses. In a corpus-based study of the functions of these items in British English, Bald (1980: 182) found that most of the yes responses constituted a tone unit of their own, whereas about half the occurrences of no are part of a tone unit. That is, yes tends to be an utterance by itself as a response whilc no is usually part of a co-utterance when it is used as a response. 


\section{The present issue}

Although I have advocated a more narrow definition of interjections above, I have not imposed my views on the contributors to this issue. As should be evident from reading the collection, each author has spent some time defining and delimiting what they think interjections are. Some have proposed classifications. Some of the contributors have even taken issue with some of the views expressed in this Introduction (see the contributions by Evans and Wilkins). In fact the contributions cover not only prototypical interjections but also interjectional phrases, emotive words and particles and even formulae. The subject matter covered in the volume represents all things that have traditionally been thought of as interjections. As far as orientation is concerned, the papers by Kryk, Wierzbicka and Wilkins are contrastive studies. These authors compare the use and meanings of functionally equivalent interjections across a number of Indo-European languages: English, Polish, Russian, Yiddish, Italian, American Sign Language and an Australian language, Mparntwe Arrernte (Aranda). The contributions by Hill (Australian English), Evans (Mayali, Australian) Juntanamalaga and Diller (Thai), Eastman (Swahili) and Ameka (Ewe) concentrate on interjectional phenomena in specific languages. ${ }^{5}$

The offerings here are also couched in various theoretical and methodological frameworks. If there is one thing that is interesting about the volume it is this: it captures the diversity and varied nature of the approaches and conceptions of interjections that exist in linguistics discourse today. Nevertheless all contributors stress one thing: the need for further investigation into the role of interjections and pragmatic constructions in general from a cross linguistic perspective. One would hope that linguists and linguistic pragmaticians in particular would take up the challenge of describing interjections in many more languages of the world.

\section{References}

Ameka, Felix, 1987. A comparative analysis of linguistic routines in two languages: English and Ewe. Journal of Pragmatics 11(3): 299-326.

5 Some of the contributors had the opportunity to read the papers of their colleagues before finalising theirs. Consequently, some of the papers speak to each other and there is a fair amount of debate and dialogue on some of the common themes. For instance, the papers by Wilkins and Evans complement each other as far as the interpretation of interjections is concerned. Wilkins argues that interjections can be decomposed into propositions and the referents of the arguments are contextually supplied through deictic substitution. Evans goes a step further and argues that deictic substitution alone is not enough and that some interjections require processes of conversational inference for their full interpretation. Similarly, Wierzbicka's assertion that interjections are not speech acts is challenged in Wilkins's paper. Both views are critically examined in Ameka's contribution. 
Ameka, Felix, 1992. The meaning of phatic and conative interjections. Journal of Pragmatics 18: 245-271 (this issue).

Bald, Wolf-Dietrich, 1980. Some functions of yes and no in conversation. In: Sidney Greenbaum, Geoffrey Leech and Jan Svartvik, eds., Studies in English linguistics: For Randolph Quirk, 178191. London: Longman.

Bühler, Karl, 1934. Sprachtheorie. Jena: Fischer. [Reprinted Stuttgart: Fischer, 1965.]

Bursill-Hall, Geoffrey Lesley, 1971. Speculative grammars of the middle ages. The Hague: Mouton.

Bursill-Hall, Geoffrey Lesley, 1972. Thomas of Erfurt: Grammatica speculativa. An edition with translation and commentary by G.L. Bursill-Hall. London: Longman.

Bynon, James, 1976. Domestic animal calling in a Berber tribe. In: William C. McCormack and Stepehen Wurm, eds., Language and man: Anthropological issues, 39-65. The Hague: Mouton.

Coulmas, Florian, ed., 1981. Conversational routine. The Hague: Mouton.

Eastman, Carol, 1992. Swahili interjections: Blurring language-use and gesture-use boundaries. Journal of Pragmatics 18:273-287 (this issue).

Ehlich, Konrad, 1986. Interjektionen. Tübingen: Niemeyer.

Evans, Nicholas, 1992. 'Wanjh! Bonj! Nja!': Sequential organization and social deixis in Mayali interjections. Journal of Pragmatics 18: 225-244 (this issue).

Fraser, Bruce, 1990. An approach to discourse markers. Journal of Pragmatics 14: 383-395.

Fries, Charles C., 1952. The structure of English. New York: Harcourt Brace.

Goffman, Erving, 1981. Response cries. In: Forms of talk, 78-122. Oxford: Blackwell.

Hérique, Emmanuel, in press. Etude de l'interjections tiens: Contribution à l'étude du phénomène interjectif. Tübingen: Niemeyer.

Hill, Deborah, 1992. Imprecatory interjectional constructions: Some examples from Australian English. Journal of Pragmatics 18: 209-223 (this issue).

Isačenko, A.V., 1964. On the conative function of language. In: J. Vachek, ed., A Prague School reader in linguistics, 88-97. Bloomington, IN: Indiana University Press.

Jakobson, Roman, 1960. Linguistics and poetics. In: Thomas Sebeok, ed., Style in language, 350377. Cambridge, MA: MIT Press.

James, Deborah, 1972. Some aspects of the syntax and semantics of interjections. Proceedings of the Chicago Linguistic Society 8: 162-172.

James, Deborah, 1973a. The syntax and semantics of some English interjections. Ph.D. thesis, University of Michigan.

James, Deborah, 1973b. Another look at, say, some grammatical constraints on oh, interjections and hesitations. Proceedings of the Chicago Linguistic Society 9: 242-251.

James, Deborah, 1978. The use of oh, ah, say, and well in relation to a number of grammatical phenomena. Papers in Linguistics 11: 517-535.

Jespersen, Otto, 1921. Language: Its nature, development and origin. London: George Allen and Unwin.

Jespersen, Otto, 1924. The philosophy of grammar. London: Allen and Unwin.

Juntanamalaga, Preecha and Anthony Diller, 1992. Thai pragmatic constructions: The oey paradigm. Journal of Pragmatics 18: 289-301 (this issue).

Karcevski, Serge, 1969. Introduction à l'ètude de l'interjection. In: Robert Godel, ed., The Geneva School reader in linguistics, 196-212. Bloomington. IN: Indiana University Press.

König, Ekkehard, 1991. The meaning of focus particles: A comparative perspective. London: Routledge.

Kryk, Barbara, 1992. The pragmatics of interjections: The case of Polish no. Journal of Pragmatics 18: 193-207 (this issue).

Leech, Geoffrey, Margaret Deuchar and Robert Hoogenraad, 1982. English grammar for today. London: Longman.

Laughren, Mary, 1982. A preliminary description of propositional particles in Warlpiri. In: S. Swartz, ed., Papers in Warlpiri grammar in memory of Lothar Jagst, 129-163. Darwin: Summer Institute of Linguistics. 
Lyons, John, 1977. Semantics. Cambridge: Cambridge University Press.

Matisoff, James, 1979. Blessings, curses, hopes, and fears: Psycho-ostensive expressions in Yiddish. Philadelphia, PA: Institute for the Study of Human Issues.

McDermott, A. and Charlene Senape, ed., 1980. Godfrey of Fontaine's abridgement of Boethius of Dacia's 'Modi Significandi'. Amsterdam: Benjamins.

Müller, Max, 1862. Lectures on the science of language. New York: Charles Scribner.

Östman, Jan-Ola, 1981. You know: A discourse-functional approach. Amsterdam: Benjamins. [Pragmatics and Beyond II.7]

Padley, G. A., 1985. Grammatical theory in Western Europe 1500-1700. Cambridge: Cambridge University Press.

Robins, R. H., 1979. A short history of linguistics. London: Longman [Second edition.]

Sapir, Edward, 1922. The Takelma language of southwestern Oregon. In: Franz Boas, ed., Handbook of American Indian languages, 1-296. Washington, DC: Government Printing Office.

Schachter, Paul, 1985. Parts-of-speech systems. In: T. Shopen, ed., Language typology and syntactic description, Vol. I: 3-61. Cambridge: Cambridge University Press.

Schiffrin, Deborah, 1987. Discourse markers. Cambridge: Cambridge University Press.

Schourup, Lawrence, 1985. Common discourse particles in English conversation. New York: Garland.

Stankiewicz, Edward, 1964. Problems of emotive language. In: T. Sebeok, A. Hayes and M.C. Bateson, eds., Approaches to semiotics, 239-264. The Hague: Mouton.

Trager, George L., 1964. Paralanguage: A first approximation. In: Dell Hymes, ed., Language in culture and society, 274-288. New York: Harper and Row.

Wierzbicka, Anna, 1987. English speech act verbs: A semantic dictionary. Sydney: Academic Press.

Wierzbicka, Anna, 1992. The semantics of interjection. Journal of Pragmatics 18: 159-192 (this issue).

Wilkins, David, 1992. Interjections as deictics. Journal of Pragmatics 18: 119-158 (this issue).

Williams, Temnesser, 1961. The night of the iguana. London: Secker and Warbury.

Zwicky, Arnold, 1985. Clitics and particles. Language 61: 283-305. 